ГORIGINAL ARTICLE-

Volume 12 Issue 22020

DOI: 10.21315/eimj2020.12.2.5

ARTICLE INFO

Submitted: $15-3-2020$

Accepted: 20-5-2020

Online: 30-6-2020

\section{ACADEMIC FACTORS ASSOCIATED WITH BURNOUT IN MALAYSIAN MEDICAL STUDENTS: A CROSS-SECTIONAL STUDY}

\author{
Norwati Daud ${ }^{1}$, Mohamad Najib Mat Pa ${ }^{2 *}$, Ahmad Fuad Abdul \\ Rahim², Anisa Ahmad ${ }^{2}$, Nurulhuda Mat Hassan ${ }^{1}$ \\ ${ }^{1}$ Faculty of Medicine, Universiti Sultan Zainal Abidin, \\ Kuala Terengganu, Terengganu, MALAYSIA \\ ${ }^{2}$ Medical Education Department, School of Medical Sciences, \\ Universiti Sains Malaysia, Kelantan, MALAYSIA
}

To cite this article: Daud N, Pa MNM, Rahim AFA, Ahmad A, Hassan NM. Academic factors associated with burnout in Malaysian medical students: a cross-sectional study. Education in Medical Journal. 2020;12(2):49-58. https://doi.org/10.21315/eimj2020.12.2.5

To link to this article: https://doi.org/10.21315/eimj2020.12.2.5

Mohamad Najib Mat Pa, Medical Education Department, School of Medical Sciences, Universiti Sains Malaysia, 16150 Kubang Kerian, Kelantan, Malaysia | Email: drnajib@, usm.my

\section{INTRODUCTION}

Medical programme is known to be stressful, not only because of its known academic workload but also its duration is longer than other programmes. Medical students should prepare themselves academically, psychologically and physically. Due to the programme expectations, many medical students face problems and difficulties in coping with the programme. Stress, burnout and mental health issues such as anxiety and depression are not uncommon among medical students. Due to these reasons, the prevalence of stress among medical students is high and the most common source of stress was academic-related (1-2). In addition to that, the prevalence of burnout among them is also high (3-4). The relationship between stress and burnout has been proven in many studies (5-7).

According to the 11th Edition of the International Classification of Disease, burnout is defined as follows (8):
Burnout is a syndrome conceptualised as resulting from chronic workplace stress that has not been successfully managed. It is characterised by three dimensions:

1. Feelings of energy depletion or exhaustion

2. Increased mental distance from one's job, or feelings of negativism or cynicism related to one's job

3. Reduced professional efficacy

Schaufeli and Greenglass (9) defines burnout as "a state of physical, emotional and mental exhaustion that results from long-term involvement in work situations that are emotionally demanding". A recent systematic review and meta-analysis of published literature between 2000 to 2017 showed that the mean score of all the burnout scales was higher in medical students than the comparative group of post-secondary education population (10). A literature review of published studies between 1989 and 2016 in China found 
that the prevalence was between $25.8 \%$ and $71.1 \%(11)$. Frajerman et al. also did a meta-analysis on burnout among preresidency medical students from published literature between 2010 and 2017 (12). From 24 studies and 17,431 medical students, the overall prevalence was $44.2 \%$.

Studies on burnout among medical students in Saudi Arabia showed that the prevalence of burnout was $67.9 \%$ and $76.8 \%$ (13, 14). In contrast, the prevalence of burnout among medical students in Oman was low (7.4\%) (15). A recent study among medical students in England showed that $85 \%$ had exhaustion (16). A local study among medical students in Universiti Sains Malaysia (USM) showed that the prevalence of burnout was $67.9 \%$ as measured by the Copenhagen Burnout Inventory (CBI) (17). Among the domains, personal burnout was the highest $(81.6 \%)$, followed by workrelated burnout $(73.7 \%)$ and client-related burnout (68.6\%).

Burnout may start as early as in the first year of the medical course which can be as high as $75 \%$ (18). Burnout in medical students can be persistent throughout the medical course (19). It was also associated with psychological stress. Psychiatric illnesses, high workload, low self-esteem and excessive worries were associated with burnout (20). Burnout is not only prevalent among medical students, but it is also prevalent among medical doctors. A local study by Al-Dubai et al. showed that the prevalence of emotional burnout among medical interns (house officers) in Malaysia as measured using Maslach Burnout Inventory (MBI) was $36.6 \%$ (21). The study involved 191 house officers working in various specialities in Hospital Tengku Ampuan Rahimah, Klang. Burnout score was higher in those being male, Malay, married, international graduate, who, in medical or obstetrics and gynaecology rotation and of senior residents. However, only working long hours and rotations in medical or obstetrics and gynaecology were statistically significant. Predictors for burnout were average undergraduate performance, Malay, personal and home-life conflict, poor relationship with supervisor and feeling of being underpaid. Protective factors against burnout were shorter work duration, shift work and effective supervisor feedback.

There are many factors that may lead medical students to develop burnout during medical school. Low support from friends, being in clinical years and being female were associated with burnout (22). Burnout was found to be significantly higher in those with no hobbies and no time to exercise or pray (23). Poor social support, dissatisfaction with lecturer and poor satisfaction with education were among the factors associated with burnout (24).

Burnout should be examined in medical students as it is associated with several negative impacts. It is associated with physical health complaints, mental health issues such as depression and anxiety, substance abuse such as alcohol and drugs and poor academic performance (25-26). Dyrbye et al. showed that burnout predicts suicidal ideation among medical students in the United States (27). The study also indicated that the prediction of suicidal ideation in students with burnout was dose-related. Each 1-point increase in emotional exhaustion and depersonalisation scores and 1-point decrease in personal accomplishment scores was associated with $5 \%, 10 \%$ and $6 \%$ increase in the odds of suicidal ideation respectively in the following year.

Since there are many studies looking at the prevalence of burnout in medical students and its associated factors, this study aimed to determine the prevalence of burnout with a focus on academic factors associated with burnout among medical students in a new public medical school in Malaysia. 


\section{METHODS}

A cross-sectional study was conducted among medical students in a new public medical school in Malaysia. The study was done between November 2019 and January 2020. It involved 200 medical students who were selected using stratified random sampling based on gender, race and year of study. There were 40 students invited from each year. The minimum sample size calculated was 175 based on the objectives and $80 \%$ power.

\section{Study Instrument}

The study used the Malay translation of Copenhagen Burnout Inventory (CBI-M) to measure burnout. Copenhagen Burnout Inventory (CBI) was developed by Kristensen and colleagues and published in 2005 (28). The domains in the CBI are personal burnout, work-related burnout and client-related burnout. There are six items under personal burnout, seven items under work-related burnout and six items under client-related burnout. Personal burnout is defined as "the degree of physical and psychological fatigue and exhaustion experienced by the person". The items under this domain enquire about the personal experience of tiredness, worn out, exhaustion, both physical and emotion and the implication of these symptoms related to susceptibility to illness and feeling of inability to cope. Work-related burnout is defined as "the degree of physical and psychological fatigue and exhaustion that is perceived by the person as related to his/her work". Items under this domain focus on the implication of work on his/her feelings of worn-out, exhaustion, tiredness, lack of energy for social relationship, burntout and frustration. CBI was tested on 1,914 participants from various types of workplaces. The Cronbach's alpha value for personal burnout was 0.87 , work-related burnout (0.87) and client-related burnout (0.85).
The CBI-M was validated by Chin et al. (29). Face and construct validity were done on medical students. The face validity index of clarity and comprehension were $82.7 \%$ and $85.9 \%$, respectively. The overall face validity index was $83.2 \%$. The Cronbach's alpha values of the personal burnout and work-related burnout factors were 0.85 to 0.87. However, the CBI-M has dropped one item in the work-related factor which is, "Do you have enough energy for family and friends during leisure time?" due to poor item loading into the factor.

CBI has five response categories with two formats according to the type of questions. One format is according to frequency from "always" to "never". The other format is from "a very high degree" to "a very low degree". The scoring for frequency is from 100 to 0 . The CBI authors decided not to decide on any cut-score to distinguish between a person with burnout and without burnout as they thought it may lead to loss of information. The original study was presented in mean score (28). However, some studies used a cut-off point of 50-points to identify groups with significant burnout and non-significant burnout $(30,17)$. For the purpose of this study, the words "working/work" in the original CBI were replaced with "study/academic activities" to suit the study population. A cut-off mean score of 50-points or more was used to indicate significant burnout and its two domains based on two previous studies that used the same cut-off point $(30,17)$. In this study, the client-related scale was dropped as it was not applicable to medical students.

\section{Data Collection Procedure}

The timing of the data collection was scheduled so that it would not be within two weeks prior or after the end of semester or posting examination for each year/ group to avoid bias in the results. Prior to data collection, students were assured that participation in this study was entirely voluntary and would have no academic implication from the study. 
The study questionnaire was distributed in Google Forms format using WhatsApp Messenger application. The questionnaire contained basic personal data, entry CGPA and whether they made the correct decision to do medicine, were satisfied with course activities, ever failed in any examination, were confident in passing medicine in five years and ever thought of dropping out. The response was in the form of "yes/no". At the end of the questionnaire, an optional information on participants' contact number was provided. This information was for those who were interested to know their results or those who thought that they had burnout symptoms and needed further assistance.

\section{Data Analysis}

Data was analysed using the IBM SPSS ${ }^{\circledR}$ (Statistical Package for the Social Sciences) software version 20. Burnout was categorised into significant and nonsignificant burnout based on the mean CBI-M score. Descriptive statistic was used to generate the prevalence of significant burnout. Each factor was analysed using chi-square test to determine its association with burnout. Entry CGPA was analysed using independent $t$-test. For all analysis, significance level was set at 0.05 .

\section{Ethics Approval}

This research was approved by Universiti Sultan Zainal Abidin Human Research Ethics Committee on 21 October 2019 (UniSZA.C/2/UHREC/628-2Jld 2(14)).

\section{RESULTS}

The number of participants who consented and responded to the online questionnaire was 182, fulfilling the minimum sample size of 175 . The percentage of response was $91.0 \%$. The socio-demographics of the participants is presented in Table 1.
Table 1: Socio-demography of the participants

$$
(n=182)
$$

\begin{tabular}{lrrr}
\hline Variables & \multicolumn{1}{c}{$\boldsymbol{n}$} & $\%$ & Mean (SD) \\
\hline Gender & & & \\
$\quad$ Male & 53 & 29.1 & \\
$\quad$ Female & 129 & 70.9 & \\
Race & & & \\
$\quad$ Malay & 123 & 67.6 & \\
$\quad$ Indian & 47 & 25.8 & \\
$\quad$ Chinese & 12 & 6.6 & \\
Year of study & & & \\
1 & 37 & 20.3 & \\
2 & 40 & 22.0 & \\
3 & 33 & 18.1 & \\
4 & 35 & 19.2 & \\
5 & 37 & 20.3 & \\
CGPA & & & 3.94 (0.14) \\
$3.60-3.69$ & 1 & 0.5 & \\
$3.70-3.79$ & 6 & 3.3 & \\
$3.80-3.89$ & 27 & 14.8 & \\
$3.90-4.00$ & 148 & 81.3 & \\
\hline
\end{tabular}

Majority of the participants were female and Malay, representing the composition of students in the medical school. Each year had an almost equivalent number. Majority were with CGPA 3.90 and above.

The prevalence of significant burnout was $36.8 \%$ (95\% CI: $29.8 ; 44.3$ ). For personal burnout, the prevalence was $54.9 \%$ (95\% CI: 47.4;62.3) while for work-related burnout, the prevalence was $31.9 \%$ (95\% CI: 25.2;39.2). The results show that personal burnout affects more to the overall students' burnout than work-related burnout.

The percentage of burnout by gender, race, year and entry CGPA category is shown in Table 2 .

Significant burnout was higher in male, Malay, third year and those in the lowest CGPA category. 
Table 2: Percentage of burnout by gender, race, year and entry CGPA category $(n=182)$

\begin{tabular}{lcc}
\hline \multirow{2}{*}{ Variables } & \multicolumn{2}{c}{ Burnout } \\
\cline { 2 - 3 } & $\begin{array}{c}\text { Significant } \\
\boldsymbol{n}(\%)\end{array}$ & $\begin{array}{c}\text { Non-significant } \\
\boldsymbol{n}(\%)\end{array}$ \\
\hline Mender & & $33(62.3 \%)$ \\
Female & $20(37.7 \%)$ & $82(63.6 \%)$ \\
Race & $47(36.4 \%)$ & \\
Malay & $46(37.4 \%)$ & $77(62.6 \%)$ \\
Indian & $17(36.2 \%)$ & $30(63.8 \%)$ \\
Chinese & $4(33.3 \%)$ & $8(66.7 \%)$ \\
Year of study & & \\
1 & $8(21.6 \%)$ & $29(78.4 \%)$ \\
2 & $16(40.0 \%)$ & $24(60.0 \%)$ \\
3 & $18(54.5 \%)$ & $15(45.5 \%)$ \\
4 & $12(34.3 \%)$ & $23(65.7 \%)$ \\
5 & $13(35.1 \%)$ & $24(64.9 \%)$ \\
Entry CGPA & & \\
$3.60-3.79$ & $5(50 \%)$ & $5(50 \%)$ \\
$3.80-3.89$ & $6(25 \%)$ & $18(75 \%)$ \\
$3.90-4.00$ & $56(37.8 \%)$ & $92.2 \%)$ \\
\hline
\end{tabular}

\section{ASSOCIATION BETWEEN ACADEMIC FACTORS AND BURNOUT}

Factors associated with burnout were analysed using chi-square test for categorical variables and independent $t$-test for numerical variables. Results are as shown in Table 3.

Incorrect decision in choosing medical course, unsatisfied with the course and thinking of dropping out are significantly associated with burnout.

\section{DISCUSSION}

The prevalence of burnout among medical students vary from country to country with no specific pattern. Some countries showed low prevalence while some showed high prevalence. Erchens et al. summarised in their systematic literature review and metaanalysis that the prevalence was between $7.0 \%$ and $75.2 \%$, depending on the instrument and cut-off point used (10).

Table 3: Association between academic factors and burnout

\begin{tabular}{|c|c|c|c|c|c|c|}
\hline \multirow[b]{2}{*}{ Variables } & & \multicolumn{2}{|c|}{ Burnout } & \multirow[b]{2}{*}{$X^{2}$ (df) } & \multirow{2}{*}{$\begin{array}{l}t \text { statistics } \\
\text { (df) }\end{array}$} & \multirow[b]{2}{*}{$p$-value } \\
\hline & & $\begin{array}{c}\text { Significant } \\
n(\%)\end{array}$ & $\begin{array}{c}\text { Non-significant } \\
n(\%)\end{array}$ & & & \\
\hline \multirow{2}{*}{$\begin{array}{l}\text { Made correct decision in } \\
\text { choosing medical course }^{\text {a }}\end{array}$} & Yes & $55(32.9)$ & $112(67.1)$ & \multirow[t]{2}{*}{$13.107(1)$} & & \multirow[t]{2}{*}{$<0.001^{*}$} \\
\hline & No & $12(80.0)$ & $3(20.0)$ & & & \\
\hline \multirow[t]{2}{*}{ Satisfied with the course ${ }^{a}$} & Yes & $56(33.5)$ & $111(66.5)$ & \multirow[t]{2}{*}{$9.373(1)$} & & \multirow[t]{2}{*}{$0.020^{*}$} \\
\hline & No & $11(73.3)$ & $4(26.7)$ & & & \\
\hline \multirow[t]{2}{*}{ Ever failed any course exam ${ }^{a}$} & Yes & $28(45.9)$ & $33(54.1)$ & \multirow[t]{2}{*}{$3.258(1)$} & & \multirow[t]{2}{*}{0.071} \\
\hline & No & $39(32.2)$ & $82(67.8)$ & & & \\
\hline \multirow{2}{*}{$\begin{array}{l}\text { Confident in passing in five } \\
\text { years }^{a}\end{array}$} & Yes & $56(35.3)$ & $101(64.7)$ & \multirow[t]{2}{*}{$1.138(1)$} & & \multirow[t]{2}{*}{0.286} \\
\hline & No & $12(46.2)$ & $14(53.8)$ & & & \\
\hline \multirow[t]{2}{*}{ Thinking of dropping out ${ }^{a}$} & Yes & $35(57.4)$ & $26(42.6)$ & \multirow[t]{2}{*}{$16.680(1)$} & & \multirow[t]{2}{*}{$<0.001^{*}$} \\
\hline & No & $32(26.4)$ & $89(73.6)$ & & & \\
\hline Entry CGPA ${ }^{\mathrm{b}}$ & & $3.95(0.07)^{c}$ & $3.96(0.07)^{c}$ & & $0.366(180)$ & 0.668 \\
\hline
\end{tabular}


The present study showed that the prevalence of high burnout among medical students in a new medical school in Malaysia was $36.8 \%$. Comparing this finding with a local study among Universiti Sains Malaysia (USM) medical students, the prevalence of significant burnout using the same tool was $67.9 \%(20)$. The significant difference could be due to the difference in curriculum content and delivery, learning environment, physical and social support and resilience and coping of the students. The other two obvious differences between the two institutions are the presence of postgraduate programmes and the higher number of medical students in USM than that of the place of current study.

A recent study was done by Wing et al. in 2018 on Malaysian students studying in Malaysia as well as overseas (31). From the study, the prevalence of burnout among medical students using CBI was $27.3 \%$, lower than the present study. However, their study showed that the prevalence of burnout was higher in medical students than in non-medical students $(27.3 \%$ vs. $20.1 \%)$ and the odd ratio (OR) was 1.50 . Their study included varieties of students from medical schools in Malaysia and abroad with different curriculum and different learning environment. Using subjects from different sites may have reduced the rate and may be a better representative of medical students as a whole.

In the present study, entry CGPA was not associated with burnout although the rate of burnout was shown to be higher in the low CGPA group. As entry CGPA was retrospective performance, therefore it may be the reason why the relationship was not seen. When looking at the relationship between burnout and academic performance in medical students, burnout was associated with lower academic motivation, academic achievement and poorer quality of life (32). A study in Turkey also found that burnout was associated with reduced academic efficacy across students from multiple programmes (33). Assuming that students with high CGPA grades are hardworking and conscientious, this personality was shown to be associated with burnout (34).

A study by Costa et al. in 2012 found that factors associated with burnout were gender, dissatisfaction with the course choice, thoughts of dropping out of the course, lack of confidence in acquisition of skills, dissatisfaction with teaching strategies, feeling uncomfortable in academic activities and not seeing the coursework as a source of pleasure (35). A systematic review of factors associated with burnout among medical students in China showed inconsistent findings (36). Although gender was one of the factors, there was no specific gender consistently associated with burnout. Age was also found to be an inconsistent predictor. However, most studies found that the prevalence of burnout was higher in the clinical years compared to the earlier years. Being in the final year was found to be associated with a higher score in depersonalisation component of MBI (37). Another study in Australia showed that the MBI score significantly increased over time from the final year of undergraduates to during their internship (38). At baseline during student time, the scores were mainly lower than the comparable medical practitioners but later steadily increased after starting their internship. Clinical year was also shown to be associated with higher prevalence of burnout (13-14, 36). Dahlin and Runeson found that the mean score for exhaustion and disengagement was highest in the early clinical years compared to in the first year and the final year (20).

Mathew, in her thesis did a literature review on factors associated with burnout (39). She summarised that burnout was not associated with age but positively associated with higher year in medical school, being female and stress. It was negatively associated with sleep, spirituality and social support. Other socio-demography factors such as age and marital status were also found not to be associated with burnout (3, 40-41). Mangione et al. showed that medical students who were exposed to literature, music, theatre, and visual arts play had 
reduced burnout (42). Similarly, students who had extra-curricular activities had lower burnout experience (18). When relating the personality of medical residents with burnout, those with burnout were less likely to have a calm personality and less intention to pursue speciality training (43).

Although personality is not one of the factors studied in the current study, previous research showed that personality is related to burnout. The personality that is mostly used in the literature is the big five personality; neuroticism, agreeableness, openness, extraversion and conscientious. Swider and Zimmerman did a metaanalysis on the relationship between the big five personality and burnout (44). While neuroticism had a positive correlation with emotional exhaustion $(r=0.44)$ the other four types of personality showed a negative correlation. A 12-year prospective study was done by McManus et al. looking at the personality type and learning style of medical students at application and compared them with burnout and stress when they are at housemanship and posthousemanship level (45). They found that neuroticism was associated with stress, disorganised work and high perceived workload, agreeableness with supportivereceptive environment, openness to experience with deep approach to work, conscientious with organised work and extraversion with deep approach to work. It was hypothesised that neuroticism type personality was associated with negative outcomes at work in terms of stress and burnout.

\section{CONCLUSION AND RECOMMENDATION}

Burnout is prevalent among medical students. However, the prevalence varies from country to country and even within the same country. The present study showed that the prevalence of burnout in one of the new medical schools in Malaysia, is at average percentage compared to another university in Malaysia as well as in other countries. Burnout was found to be associated with some academic factors such as having made the correct choice for medicine, satisfaction with the course and the thought of dropping out. Initiatives to prevent and mitigate burnout among medical students by taking some actions are recommended. Activities to increase awareness and prevent burnout may be incorporated in the medical curriculum such as in personal and professional development course.

\section{ACKNOWLEDGEMENTS}

We would like to thank all students who had participated in the study and the institutions which had granted and supported the study.

\section{REFERENCES}

1. Yusoff MSB, Yee LY, Wei LH, Meng LH, Bin LX, Siong TC, Rahim AFA. A study on stress, stressors and coping strategies among Malaysian medical students. International Journal of Students' Research. 2011;1(2): 45-50. https://doi.org/10.5549/ijsr.1.2.45-50

2. Siraj HH, Salam A, Roslan R, Hasan NA, Jin TH, Othman MN. Stress and its association with the academic performance of undergraduate fourth year medical students at Universiti Kebangsaan Malaysia. International Medical Journal Malaysia 2014;3(1):19-24.

3. Prins JT, Gazendam-Donofrio SM, Tubben B J, Van Der Heijden FMMA, Van De Wiel, HBM, Hoekstra-Weebers JEHM. Burnout in medical residents: a review. Medical Education. 2007;41(8):788-800. https://doi .org/10.1111/j.1365-2923.2007.02797.x

4. Imo UO. Burnout and psychiatric morbidity among doctors in the UK: a systematic literature review of prevalence and associated factors. BJPsych Bulletin 2017;41(4): 197-204. https://doi.org/10.1192/pb.bp.116 .054247 
5. McManus IC, Winder BC, Gordon D. The causal links between stress and burnout in a longitudinal study of UK doctors. Lancet 2002;359(9323):2089-90. https://doi.org/10 .1016/S0140-6736(02)08915-8

6. Wu S, Zhu W, Wang Z, Wang $M$, Lan Y. Relationship between burnout and occupational stress among nurses in China. Journal of Advanced Nursing 2007;59(3):233-9. https://doi.org/10.1111/ j.1365-2648.2007.04301.x

7. Khamisa N, Peltzer K, Ilic D, Oldenburg B. Effect of personal and work stress on burnout, job satisfaction and general health of hospital nurses in South Africa. Health SA Gesondheid 2017;22:252-8. https://doi .org/10.1016/j.hsag.2016.10.001

8. World Health Organization. International classification of diseases. 11th ed.; 2019. https://icd.who.int/browse1 1/1-m/en

9. Schaufeli WB, Greenglass ER. Introduction to special issue on burnout and health. Psychol Health 2001;16(5):501-10. https:// doi.org/10.1080/08870440108405523

10. Erschens R, Keifenheim KE, HerrmannWerner A, Loda T, Schwille-Kiuntke J, Bugaj TJ, et al. Professional burnout among medical students: systematic literature review and meta-analysis. Medical Teacher 2019;41(2):172-83. https://doi.org/10.1080/ 0142159X.2018.1457213

11. Chunming WM, Harrison R, MacIntyre $\mathrm{R}$, Travaglia J, Balasooriya C. Burnout in medical students: a systematic review of experiences in Chinese medical schools. BMC Medical Education 2017;17(1):1-11. https://doi.org/10.1186/s12909-017-1064-3

12. Frajerman A, Morvan $\mathrm{Y}$, Krebs MO, Gorwood P, Chaumette B. Burnout in medical students before residency: a systematic review and meta-analysis. European Psychiatry 2019;55:36-42. https:// doi.org/10.1016/j.eurpsy.2018.08.006
13. Aboalshamat $K$, Alzahrani $M$, Rabie $N$, Alharbi R, Joudah R, Khulaysi S, Alansari W. The relationship between burnout and perfectionism in medical and dental students in Saudi Arabia. Journal of Dental Specialities 2017;5(2):122-7. https://doi.org/ $10.18231 / 2393-9834.2017 .0029$

14. El-Masry R, Ghreiz SMI, Shams TM, Helal RM. Perceived stress and burnout among medical students during clinical period. Ibnosina Journal of Medicine and Biomedical Sciences 2012;5(4):179-88. Retrieved from http://journals.sfu.ca/ijmbs/ index.php/ijmbs/article/view/316

15. Al-Alawi M, Al-Sinawi H, Al-Qubtan A, AlLawati J, Al-Habsi A, Al-Shuraiqi M, et al. Prevalence and determinants of burnout syndrome and depression among medical students at Sultan Qaboos University: a cross-sectional analytical study from Oman. Arch Environ Occup Health. 2019;74(3):130-9. https://doi.org/10.1080/1 9338244.2017.1400941

16. Farrell SM, Kadhum $M$, Lewis $T$, Singh G, Penzenstadler L, Molodynski A. (2019). Wellbeing and burnout amongst medical students in England. Int Rev Psychiatry. 2019;31(7-8):579-83. https://doi.org/10.108 0/09540261.2019.1675960

17. Chin RWA, Chua YY, Chu MN, Mahadi NF, Yusoff MSB, Wong MS, Lee YY. Prevalence of burnout among Universiti Sains Malaysia medical students. Education in Medicine Journal 2016;8(3):61-74. https://doi.org/10.5959/eimj.v8i3.454

18. Fares J, Saadeddin Z, Al Tabosh H, Aridi $\mathrm{H}$, El Mouhayyar C, Koleilat MK, et al. Extracurricular activities associated with stress and burnout in preclinical medical students. J Epidemio Global Health. 2016;6(3):177-85. https://doi.org/10.1016/j. jegh.2015.10.003

19. Guthrie E, Black D, Creed F, Shaw C. Stress and burnout in medical students. J Royal Soc Med. 1998;91:237-43. 
20. Dahlin ME, Runeson B. Burnout and psychiatric morbidity among medical students entering clinical training: a three-year prospective questionnaire and interview-based study. BMC Med Educ. 2007;7:1-8. https://doi.org/10.1186/1472 $-6920-7-6$

21. Al-Dubai SAR, Ganasegeran K, Perianayagam W, Rampal KG. Emotional burnout, perceived sources of job stress, professional fulfillment, and engagement among medical residents in Malaysia. The Scientific World Journal 2013;Article ID 137620. https://doi. org/10.1155/2013/137620

22. Dahlin M, Joneborg N, Runeson B. Performance-based self-esteem and burnout in a cross-sectional study of medical students. Med Teach. 2007;29(1):43-8. https://doi.org/10.1080/01421590601175309

23. Asghar AA, Faiq A, Shafique S, Siddiqui F, Asghar N, Malik S, et al. Prevalence and predictors of the burnout syndrome in medical students of Karachi, Pakistan. Cureus 2019;11(6):e4879. https://doi.org/ $10.7759 /$ cureus. 4879

24. Haile YG, Senkute AL, Alemu BT, Bedane DM, Kebede KB. Prevalence and associated factors of burnout among Debre Berhan University medical students: a cross-sectional study. BMC Med Educ. 2019;19(1):1-11. https://doi.org/10.1186/ s12909-019-1864-8

25. Balch CM. Stress and burnout among surgeons. Archives of Surgery 2009;144(4):371. https://doi.org/10.1001/ archsurg.2008.575

26. Gorter RC, Eijkman MAJ, Hoogstraten J. Burnout and health among Dutch dentists. Euro J Oral Sci. 2000;108(4): 261-7. https://doi.org/10.1034/j.1600-0722 $.2000 .108004261 . x$
27. Dyrbye LN, Thomas MR, Massie FS, Power DV, Eacker A, Harper W, et al. Burnout and suicidal ideation among US medical students. Ann Intern Med. 2008;149(5):334-41.

28. Kristensen TS, Borritz M, Villadsen E, Christensen KB. The Copenhagen burnout inventory: a new tool for the assessment of burnout. Work and Stress 2005;19(3):192-207. https://doi.org/10.1080/ 02678370500297720

29. Chin RWA, Chua YY, Chu MN, Mahadi NF, Wong MS, Yusoff MS, Lee YY. Investigating validity evidence of the Malay translation of the Copenhagen Burnout Inventory. J Taibah University Med Sci. 2018;13(1):1-9.

30. Jepsen I, Juul S, Foureur M, Sørensen EE, Nøhr EA. Is caseload midwifery a healthy work-form? A survey of burnout among midwives in Denmark. Sexual \& Reproductive Healthcare 2017;11:102-6.

31. Wing T, Pey Y, Subramaniam V, Raof N, Ting O, Ahmad M. Prevalence of burnout in medical and non-medical undergraduate Malaysian Students in various International Universities: a cross-sectional study. Journal of Advances in Medicine and Medical Research 2018;25(11):1-13. https://doi.org/ $10.9734 / \mathrm{jammr} / 2018 / 40212$

32. Lyndon MP, Henning MA, Alyami $H$, Krishna S, Zeng I, Yu TC, Hill AG. Burnout, quality of life, motivation, and academic achievement among medical students: a person-oriented approach. Perspectives on Medical Education 2017;6(2):108-14. https://doi.org/10.1007/ s40037-017-0340-6

33. Duru E, Duru S, Balkis M. Analysis of relationships among burnout, academic achievement, and self-regulation. Educational Sciences: Theory \& Practice 2014;14(4):1274-84. https://doi.org/10 .12738/estp.2014.4.2050 
34. David AP. Examining the relationship of personality and burnout in college students: the role of academic motivation. Educational Measurement and Evaluation Review 2010;1(July):90-104.

35. Costa EF de O, Santos SA, Santos ATR de A, de Melo EV, de Andrade TM. Burnout Syndrome and associated factors among medical students: a cross-sectional study. Clinics 2012;67(6):573-9. https://doi.org/10 $.6061 /$ clinics $/ 2012(06) 05$

36. Chunming WM, Harrison R, MacIntyre $\mathrm{R}$, Travaglia J, Balasooriya C. Burnout in medical students: a systematic review of experiences in Chinese medical schools. BMC Med Educ. 2017;17(1):1-11. https:// doi.org/10.1186/s12909-0171064-3

37. Cecil J, McHale C, Hart J, Laidlaw A. Behaviour and burnout in medical students. Med Educ. Online 2014;19(April):25209. https://doi.org/10.3402/meo.v19.25209

38. Willcock SM, Daly MG, Tennant CC, Allard BJ. Burnout and psychiatric morbidity in new medical graduates. Medical Journal of Australia 2004;181(7):357-60. https://doi.org/10.5694/j.1326-5377.2005 .tb06834.x

39. Mathew R. Factors associated with burnout in medical students (dissertation). Tucson, US : University of Arizona; 2017.

40. Sepehrmanesh Z, Ahmadvand A, Akasheh G, Saei R. P02-119 - Prevalence of burnout in senior medical students. European Psychiatry 2010;25:723. https://doi.org/10 $.1016 / \mathrm{s} 0924-9338(10) 70717-3$
41. Yazdi Z, Abbasi M, Kazemifar AM. Prevalence of burnout syndrome in the beginning and end of internship course in medical students of Qazvin University of Medical Sciences. Journal of Medical Education. 2018;17(1):1-8.

42. Mangione S, Chakraborti C, Staltari G, Harrison R, Tunkel AR, Liou KT, et al. (2018). Medical students' exposure to the humanities correlates with positive personal qualities and reduced burnout: a multiinstitutional U.S. survey. J Gen Intern Med. 2018; 33:628-34. https://doi.org/10.1007/ s1 1606-017-4275-8

43. Ripp J, Babyatsky M, Fallar R, Bazari H, Bellini L, Kapadia C, et al. The incidence and predictors of job burnout in first-year internal medicine residents: A five-institution study. Acad Med. 2011;86(10):1304-10. https://doi. org/10.1097/ACM.0b013e31822c1236

44. Swider BW, Zimmerman RD. Born to burnout: a meta-analytic path model of personality, job burnout, and work outcomes. Journal of Vocational Behavior. 2010;76(3):487-506. https:/doi. org/10.1016/j.jvb.2010.01.003

45. McManus IC, Keeling A, Paice E. Stress, burnout and doctors' attitudes to work are determined by personality and learning style: a twelve-year longitudinal study of UK medical graduates. BMC Med. 2004;2(1):29. 